\title{
Should Heavy Metals Be Monitored in Foods Derived From Soils Fertilized With Animal Waste?
}

\begin{abstract}
Rafael da Rosa Couto ${ }^{1 *}$, Jucinei J. Comin ${ }^{2}$, Monique Souza ${ }^{2}$, Felipe K. Ricachenevsky ${ }^{3,4}$, Marcos A. Lana ${ }^{5,6}$, Luciano C. Gatiboni ${ }^{7}$, Carlos A. Ceretta ${ }^{8}$ and Gustavo Brunetto ${ }^{8}$

${ }^{1}$ Técnico em Agroecologia, Instituto Federal Catarinense, Rio do Sul, Brazil, ${ }^{2}$ Agroecossistemas, Centro de Ciências Agrárias, Universidade Federal de Santa Catarina, Florianópolis, Brazil, ${ }^{3}$ Departamento de Biologia, Agrobiologia, Universidade Federal de Santa Maria, Santa Maria, Brazil, ${ }^{4}$ Biologia Celular e Molecular, Universidade Federal do Rio Grande do Sul, Porto Alegre, Brazil, ${ }^{5}$ Department of Crop Production Ecology, Swedish University of Agricultural Sciences, Uppsala, Sweden, ${ }^{6}$ SUSLAND, Leibniz Centre for Agricultural Landscape Research, Müncheberg, Germany, ${ }^{7}$ Ciência do Solo, Centro de Ciências Agroveterinárias, Universidade do Estado de Santa Catarina, Lages, Brazil, ${ }^{8}$ Ciência do Solo, Departamento de Solos, Universidade Federal de Santa Maria, Santa Maria, Brazil
\end{abstract}

Keywords: heavy metals, animal waste, soil fertilization, residue management, seed contamination

OPEN ACCESS

Edited by:

Jose M. Garcia-Mina

Universidad de Navarra, Spain

Reviewed by:

Heitor Cantarella

Instituto Agronômico de Campinas

(IAC), Brazil

Lourdes Hernandez-Apaolaza, Universidad Autonoma de Madrid,

Spain

*Correspondence:

Rafael da Rosa Couto rrccouto@hotmail.com

Specialty section: This article was submitted to Plant Nutrition, a section of the journal

Frontiers in Plant Science

Received: 21 February 2018 Accepted: 15 May 2018

Published: 05 June 2018

Citation:

da Rosa Couto R, Comin JJ, Souza M, Ricachenevsky FK

Lana MA, Gatiboni LC, Ceretta CA and Brunetto G (2018) Should Heavy Metals Be Monitored in Foods Derived

From Soils Fertilized With Animal Waste? Front. Plant Sci. 9:732. doi: 10.3389/fp/s.2018.00732
Heavy metals (HM) represent a large group of elements with atomic density $>5 \mathrm{~g} \mathrm{~cm}^{-3}$ or atomic number $>20$ (Saidur et al., 2017), among which some are essential to plants, such as iron (Fe), zinc $(\mathrm{Zn})$, copper $(\mathrm{Cu})$, nickel $(\mathrm{Ni})$, and manganese $(\mathrm{Mn})$. However, HMs may be contaminants and/or pollutants, depending on the concentration in soils.

HMs such as $\mathrm{Cu}, \mathrm{Zn}, \mathrm{Ni}$, and chromium $(\mathrm{Cr})$ are essential to human beings, and biofortification approaches to improve levels of some elements in plant edible parts are underway (Bouis et al., 2012; Ricachenevsky et al., 2015). However, these HMs may be toxic if accumulated, and may only be ingested in very small quantities (EPA-U.S. Environmental Protection Agency, 1995; FAO-Food Agriculture Organization of the United Nations, 1995; Tchounwou et al., 2012). On the other hand, $\mathrm{Pb}, \mathrm{Cd}, \mathrm{As}$, and $\mathrm{Br}$ are not essential and can be toxic even at low concentrations (Tchounwou et al., 2012). The safe daily intake level for As, Cd, Cr, $\mathrm{Cu} \mathrm{Ni}, \mathrm{Pb}$, and $\mathrm{Zn}$ is 20, 300, 1500, 4, 20, 40, 300 $\mu \mathrm{g} \mathrm{kg}^{-1}$ of body weight per day, respectively (EPA-U.S. Environmental Protection Agency, 1993). These levels are based on the degree to which the element may cause disturbance, the capacity of the body to accumulate the element and the weight of the individual who is ingesting it (Abbasi et al., 2013). However, when HMs are ingested for long periods, even at doses considered safe, they can cause harmful effects, known as chronic intoxication (Jorge Mendoza et al., 2017; Li et al., 2017).

The increase in total HM concentration and their chemical forms in soils can occur naturally due to atmospheric deposition, weathering of rocks, and anthropic activities such as mining, deposition of ash from coal burning, application of pesticides in plants, addition of mineral and organic fertilizers, among others (Guilherme et al., 2005). HM accumulation in the soil is typically assessed by indicators such as Geo-accumulation index (Igeo) (Equation 1) (Müller, 1979) and Enrichment Factor (EF) (Equation 2) (Abbasi et al., 2013) that allow the identification of the presence and the intensity of deposition of anthropogenic contaminants in topsoil.

$$
\text { Igeo }=\log _{2}\left(\frac{\left[C_{n}\right]}{1.5} *\left[B_{n}\right]\right)
$$

where: $C n$ is the measured concentration in the soil for the metal $n, B n$ is the background value for the metal $n$, and the factor 1.5 is used because of possible variations of the background data due to lithological variations. 


$$
E F=\frac{\left[\frac{\text { metal }}{R E}\right] \text { sample }}{\left[\frac{\text { metal }}{R E}\right] \text { control }}
$$

where: $R E$ is the value of metal, adopted as Reference Element.

High HM concentrations in soils may cause intoxication upon inhalation, contact with the skin, indirect ingestion of soil and intake of fruits, vegetables, grains, and their byproducts (Zheng et al., 2010; Chabukdhara and Nema, 2013; Chen et al., 2016; Jiang et al., 2017). Plants grown in soils contaminated/polluted with HM tend to absorb, accumulate, transport, and redistribute larger amounts of HM. This is likely due to the presence of nonselective essential element transporters. For instance, iron high affinity transporter IRT1 of the model plant Arabidopsis thaliana, which is necessary for $\mathrm{Fe}$ acquisition under iron deficiency, is known to also transport $\mathrm{Zn}, \mathrm{Mn}, \mathrm{Ni}, \mathrm{Co}$, and $\mathrm{Cd}$, possibly leading to metal toxicity under Fe deficiency (Korshunova et al., 1999; Barberon et al., 2014; Ricachenevsky et al., 2018). In rice, IRT1 might also transport $\mathrm{Zn}$ and Cd (Lee and An, 2009). Arsenic uptake is also performed by phosphate transporters (as arsenate) or by silicon transporters (as arsenite), which are not able to distinguish between these elements (Kochian et al., 2015). Thus, non-selective transport leads to accumulation of toxic elements, which might end up accumulating in grains or other harvested parts, and may change nutrient abundance and distribution (Punshon et al., 2018). These agricultural products containing high HM concentration might then be used for human consumption directly or indirectly through the intake of processed foods (Hariri et al., 2015; Avkopashvili et al., 2017).

To assess the risk of ingestion of a particular HM over the life of an individual, it is necessary to consider the period of ingestion. Therefore, indexes have been established to verify the risk that certain elements, such as HMs, could cause to human beings (Abbasi et al., 2013). A few examples of these indexes are the Health Risk Index (HRI), Target Hazard Quotient (THQ) and Target Cancer Risk (TCR) (Equation 5) (EPA-U.S. Environmental Protection Agency, 2010).

$$
H R I=\frac{\left(C_{n} x D_{n}\right)}{(R f D x B W)}
$$

where: $C_{n}$, total concentration of the metal in edible plant organ $\left(\mathrm{mg} \mathrm{kg}^{-1}\right) ; D_{n}$, daily intake $\left(\mathrm{g} \mathrm{day}^{-1}\right) ; B W$, average body weight $(\mathrm{kg})$; RfD, reference dose (EPA-U.S. Environmental Protection Agency, 2010).

$$
H Q=\frac{\left(C_{n} x D_{n} x 10^{-3} x E F_{r} x E D_{t o t}\right)}{R f D x B W_{a} x A T_{n}}
$$

where: $E F_{r}$, exposure frequency (days); $E D_{t o t}$, exposure duration (years); $A T_{n}$, average exposure time to non-carcinogenic heavy metals (e.g., $E D_{\text {tot }}$ x 365 days/year).

$$
T C R=\frac{\left(C_{n} \times D_{n} \times 10^{-3} x C P S_{0} x E F_{r} x E D_{t o t}\right)}{\left(B W_{a} x A T_{n}\right)}
$$

where: $C P S_{0}$, carcinogenic potential $\left(\mu \mathrm{gg}^{-1} \mathrm{day}^{-1}\right)$.

The effects of HM accumulation in soil, excess uptake by plants, and the risks that HM-contaminated foods can promote to human beings are commonly reported in mining regions (Qing et al., 2015; de Souza et al., 2017; Li et al., 2017). As example, the release and drifting of dust from coal mines in the Qingshui River basin (China) has resulted in pollution of arable soils. Despite the knowledge associated to the deposition of HMs, few studies approach the increase of HM concentration in different edible plant organs cultivated on soils subjected to a long history of animal waste application.

Different environmental agencies have established acceptable levels of HM in food. FAO and EPA-USA established maximum levels for $\mathrm{Cu}, \mathrm{Zn}, \mathrm{Cd}, \mathrm{Pb}, \mathrm{Cr}$, and $\mathrm{Ni}$ in crop grains of 20, 50, 0.1, $0.2,1$, and 0.04 , respectively. However, studies on soils subjected to the addition of urban sludge and animal residues reported increased HM concentration above these limits in grains, fruits, and vegetables (Suarez-Tapia et al., 2017; Zhang et al., 2017). The use of wastewater for irrigation in Iran containing 0.06, 0.010, $0.01,0.010$, and $0.010 \mathrm{mg} \mathrm{kg}^{-1}$ of $\mathrm{Cu}, \mathrm{Zn}, \mathrm{Cd}, \mathrm{Pb}, \mathrm{Cr}$, and $\mathrm{Ni}$, respectively, caused the accumulation of $\mathrm{Cd}, \mathrm{Cr}$, and $\mathrm{Pb}$ in wheat and corn grains above the limits established by the EPA. Health risks to adults and especially children by $\mathrm{Cu}, \mathrm{Cd}$, and $\mathrm{Cr}$ intake in corn and wheat grains were also reported (Asgari and Cornelis, 2015). Animal waste contains HM derived from drugs or feed (Gunkel-Grillon et al., 2015; Couto et al., 2016).

It is worth mentioning that soils with frequent application of organic wastes typically have higher HM concentrations than those described in studies where negative effects of excess HM on edible plant organs and human health risk have been reported, indicating that we might be underestimating the contamination of foods derived from such areas (Table 1). Studies that address the effects of increasing HM concentration in soils subjected to long-term animal waste application and consequent changes of HM concentration in edible plant organs are still scarce. Although organic fertilization recommendations exist both for conventional and organic production systems, the application of organic residues is often carried out indiscriminately in regard to HMs content, increasing their concentration in soils and likely increasing of HM concentration in edible plant organs (Couto et al., 2016; Suarez-Tapia et al., 2017; Zhang et al., 2017). A very important aspect is that in organic production systems, organic residues (including animal manure) are the main-if not the only-source of nutrients for the crops. Considering that organic production systems currently occupy 42 million hectares worldwide (FIBL, 2017), with a global growth rate of $4.5 \%$ per year, the risk of HM contamination in the food systems is present, especially in some regions of the world. In Brazil, Japan, and the European Union, the growth rate of the area cultivated under the organic system is 30,13 , and $8 \%$ per year, respectively (FIBL, 2017). This emergent risk indicates that the organic residues that will be used as source of nutrients for the crops needs to be assessed in terms of HM concentration.

In Brazil, the applications of pig slurry, cattle slurry, and pig deep litter for 10 years in sandy soil with low organic matter content under no-till increased $\mathrm{Ni}, \mathrm{Cu}$, and $\mathrm{Zn}$ concentrations in shoots and grains of corn and wheat (da Rosa Couto et al., 2018). 
da Rosa Conto et al.

Food Contamination From Animal Waste

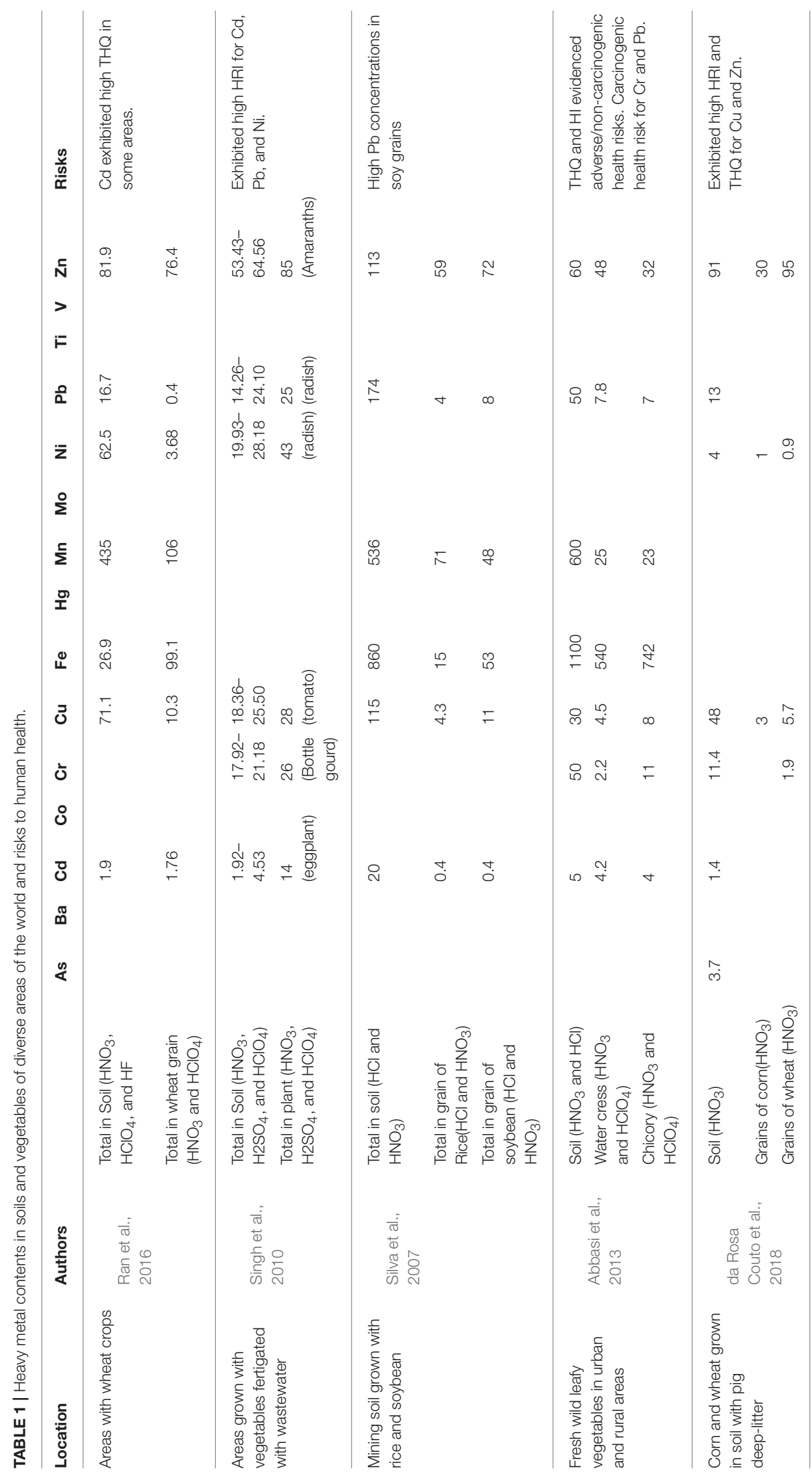

Frontiers in Plant Science | www.frontiersin.org

June 2018 | Volume 9 | Article 732 
The applications of organic wastes (pig slurry, cattle slurry, and pig deep litter) and mineral fertilizers also increased the values of HRI and THQ for $\mathrm{Br}$ and $\mathrm{Zn}$, presenting health risks to adults and especially children who have lower body weight (da Rosa Couto et al., 2018). They also report that $\mathrm{Cu}$ concentrations in corn grains of plants grown in soil with application of pig deep litter and cattle slurry were 2.7 and $2.2 \mathrm{mg} \mathrm{Cu} \mathrm{kg}^{-1}$, respectively. On the other hand, $\mathrm{Zn}$ concentrations in corn grains of plants grown in soil with application of pig deep litter, pig slurry, and cattle slurry were 26,31 , and $23 \mathrm{mg} \mathrm{Zn} \mathrm{kg}^{-1}$, respectively. In the grains of wheat grown in soil with the application of pig deep litter, pig slurry, and cattle slurry, concentrations of $\mathrm{Cu}$ were 6.0, 6.0 , and $4.5 \mathrm{mg} \mathrm{kg}^{-1}$, respectively, and $\mathrm{Zn}$ were 96,95 , and $84 \mathrm{mg}$ $\mathrm{kg}^{-1}$, respectively. Thus, $\mathrm{Cu}$ and $\mathrm{Zn}$ concentrations in grains of corn and wheat grown in soil with a long history of application of organic wastes were higher than those found in plants grown in the control soil or even with the application of mineral fertilizer. This justifies the monitoring of concentrations of elements in grains of plants grown in soils with a long history of organic waste application, especially in soils with low capacity for adsorption of elements, such as sandy soils with low organic matter (Brunetto et al., 2014).

Plants have the potential to absorb and accumulate larger amounts of several heavy metals. In studying heavy metal contents in vegetables fertilized with wastewater in India, Singh et al. (2010) found that the concentrations of Cd in plants varied from $>2$ to $15 \mathrm{mg} \mathrm{kg}^{-1}$, while $\mathrm{Pb}$ ranged from $>1$ to $28 \mathrm{mg}$ $\mathrm{kg}^{-1}$ and $\mathrm{Ni}$ from $>1$ to $41 \mathrm{mg} \mathrm{kg}^{-1}$. The authors verified a risk to consumer health (HRI $>1$ ) through the ingestion of $\mathrm{Cd}$ accumulated in radish, cabbage, cauliflower, okra, eggplant wheat and rice; of $\mathrm{Pb}$ accumulated in palak, cabbage, cauliflower, Lady's fingers, brinjal, wheat, and rice; and Ni accumulated in palak, cauliflower, wheat, and rice. However, it is important to observe the proportion of vegetables and cereals in the diet, which may change according to the culture of each place and country, causing higher or lower risk.

\section{REFERENCES}

Abbasi, A. M., Iqbal, J., Khan, M. A., and Shah, M. H. (2013). Health risk assessment and multivariate apportionment of trace metals in wild leafy vegetables from Lesser Himalayas, Pakistan. Ecotoxicol. Environ. Saf. 92, 237-244. doi: 10.1016/j.ecoenv.2013. 02.011

Asgari, K., and Cornelis, W. M. (2015). Heavy metal accumulation in soils and grains, and health risks associated with use of treated municipal wastewater in subsurface drip irrigation. Environ. Monit. Assess. 187:410. doi: 10.1007/s10661-015-4565-8

Avkopashvili, G., Avkopashvili, M., Gongadze, A., Tsulukidze, M., and Shengelia, E. (2017). Determination of $\mathrm{Cu}, \mathrm{Zn}$ and $\mathrm{Cd}$ in soil, water and food products in the vicinity of RMG gold and cupper mine, Kazreti, Georgia. Ann. Agrarian Sci. 15, 269-272. doi: 10.1016/j.aasci.2017.05.001

Barberon, M., Dubeaux, G., Kolb, C., Isono, E., Zelazny, E., and Vert, G. (2014). Polarization of Iron-regulated transporter 1 (IRT1) to the plant-soil interface plays crucial role in metal homeostasis. Proc. Natl. Acad. Sci. U.S.A. 111, 8293-8298. doi: 10.1073/pnas.1402262111

Bouis, H., Boy-Gallego, E., and Meenakshi, J. V. (2012). "Micronutrient malnutrition: prevalence, consequences and interventions," in Fertilizing Crops

\section{FINAL CONSIDERATIONS}

The use of waste as a source of nutrients in plant production systems, traditional, and organic, is common worldwide, and important strategy for nutrient cycling. However, longterm application of such waste causes the increase of HM concentrations in soils, increasing HM uptake by plants and assimilation in edible organs such as grains, as indicated by the data presented in Table 1. As different plant organs can be used in the preparation of numerous products for human consumption, it is necessary to monitor the concentrations of $\mathrm{HM}$ in edible plant organs of different species and cultivars fertilized with organic waste. This monitoring can be done through indexes such as Igeo, EF, HRI, THQ, TCR, allowing us to estimate the possible dangers of HMs to the health of children, young adults, and adults who eat food derived from plants grown in soils with a history of animal waste application. Thus, we recommend careful consideration of practices that indiscriminately use animal waste in plant production to avoid HM accumulation and health hazards to consumers. Moreover, strongly indicate that evaluation of metal contamination in foods derived from plants cultivated using animal waste should be commonplace, and further studies of how widespread that is should be conducted by the scientific community.

\section{AUTHOR CONTRIBUTIONS}

RdRC: wrote the first draft of the manuscript. MS: organized the database. JC, LG, CC: senior researchers in the field of soil science. They made specific contributions of the area. FR: senior researchers in the field of plant physiology. They made specific contributions of the area. ML: senior researchers in the field of agroecology. They made specific contributions of the area. All authors contributed to the revision of the manuscript, read and approved the version sent. to Improve Human Health: A Scientific Review, eds T. W. Bruulsema, P. Heffer, R. M. Welch, I. Cakmak, K. Moran (Norcross, GA: IPNI), 97-122.

Brunetto, G., Miotto, A., Ceretta, C. A., Schmitt, D. E., Heinzen, J., Moraes, M. P., et al. (2014). Mobility of copper and zinc fractions in fungicide-amended vineyard sandy soils. Arch. Agron. Soil Sci. 60, 609-624. doi: $10.1080 / 03650340.2013 .826348$

Chabukdhara, M., and Nema, A. K. (2013). Heavy metals assessment in urban soil around industrial clusters in Ghaziabad, India: probabilistic health risk approach. Ecotoxicol. Environ. Saf. 87, 57-64. doi: 10.1016/j.ecoenv.2012. 08.032

Chen, H., Teng, Y., Lu, S., Wang, Y., Wu, J., and Wang, J. (2016). Source apportionment and health risk assessment of trace metals in surface soils of Beijing metropolitan, China. Chemosphere 144, 1002-1011. doi: 10.1016/j.chemosphere.2015.09.081

da Rosa Couto R., Faversani, J., Ceretta, C. A., Ferreira, P. A. A., Marchezan, C., Basso Facco D. et al. (2018). Health risk assessment and soil and plant heavy metal and bromine contents in field plots after ten years of organic and mineral fertilization. Ecotoxicol. Environ. Saf. 153, 142-150. doi: 10.1016/j.ecoenv.2018.01.046

de Souza, E. S., Texeira, R. A., da Costa, H. S. C., Oliveira, F. J., Melo, L. C. A., do Carmo Freitas Faial K. et al. (2017). Assessment of risk to human 
health from simultaneous exposure to multiple contaminants in an artisanal gold mine in Serra Pelada, Pará, Brazil. Sci. Tot. Environ. 576, 683-695. doi: 10.1016/j.scitotenv.2016.10.133

Couto, R. R., Lazzari, C. J. R., Trapp, T., De Conti, L., Comin, J. J., Martins, S. R., et al. (2016). Accumulation of copper and zinc fractions in soil following the application of pig slurry for three to thirty years in a microwatershed of southern Brazil. Arch. Agron. Soil Sci. 62, 593-616. doi: 10.1080/03650340.2015.1074183

EPA-U.S. Environmental Protection Agency (1993). Reference Dose (RfD): Description and Use in Health Risk Assessments Background Document 1A. Available online at: https://www.epa.gov/iris/reference-dose-rfd-descriptionand-use-health-risk-assessments.

EPA-U.S. Environmental Protection Agency (1995). A Guide to the Biosolids Risk Assessment for the EPA Part 503 Rule, 158. Available online at: https://www.epa. gov/biosolids/guide-biosolids-risk-assessment-epa-part-503-rule

EPA-U.S. Environmental Protection Agency (2010). Risk-based Concentration Table. Available online at: https://www.epa.gov/risk

FAO-Food and Agriculture Organization of the United Nations (1995). Codex General Standard for Contaminants and Toxins in Food and Feed (codex stan 193-1995). 44p. Available online at: http://www.fao.org/fileadmin/user_upload/ livestockgov/documents/1_CXS_193e.pdf

FIBL (2017). The World of Organic Agriculture Statistics and Emerging Trends. Research Institute of Organic Agriculture (FiBL). Available online at: https:// shop.fibl.org/CHde/mwdownloads/download/link/id/785/?ref=1

Guilherme, L. R. G., Marques, J. J., Pierangeli, M. A. P., Zuliani, D. Q., Campos, M. L., and Marchi, G. (2005). Elementos-traço em solos em sistemas aquáticos. Tóp. Solo 4, 345-390. doi: 10.13140/2.1.4821.1524

Gunkel-Grillon, P., Roth, E., Laporte-Magoni, C., and Le Mestre, M. (2015). Effects of long term raw pig slurry inputs on nutrient and metal contamination of tropical volcanogenic soils, Uvéa Island (South Pacific). Sci. Tot. Environ. 533, 339-346. doi: 10.1016/j.scitotenv.2015.06.110

Hariri, E., Martine, I., Abboud, M. I., Demirdjian, S., Korfali, S., Mroueh, M., et al. (2015). Carcinogenic and neurotoxic risks of acrylamide and heavy metals from potato and corn chips consumed by the Lebanese population. J. Food Compos. Anal. 42, 91-97. doi: 10.1016/j.jfca.2015.03.009

Jiang, Y., Chao, S., Liu, J., Yang, Y., Chen, Y., Zhang, A., et al. (2017). Source apportionment and health risk assessment of heavy metals in soil for a township in Jiangsu Province, China. Chemosphere 168, 1658-1668. doi: 10.1016/j.chemosphere.2016.11.088

Kochian, L. V., Piñeros, M. A., Liu, J., and Magalhaes, J. V. (2015). Plant adaptation to acid soils: the molecular basis for crop aluminum resistance. Annu. Rev. Plant Biol. 66, 571-598. doi: 10.1146/annurev-arplant-043014-114822

Korshunova, Y. O., Eide, D., Clark, W. G., Guerinot, M. L., and Pakrasi, H. B. (1999). The IRT1 protein from Arabidopsis thaliana is a metal transporter with a broad substrate range. Plant Mol. Biol. 40, 37-44. doi: 10.1023/A:1026438615520

Lee, S., and An, G. (2009). Over-expression of OsIRT1 leads to increased iron and zinc accumulations in rice. Plant Cell Environ. 32, 408-416. doi: 10.1111/j.1365-3040.2009.01935.x

Li, H., Ji, H., Shi, C., Gao, Y., Zhang, Y., Xu, X., et al. (2017). Distribution of heavy metals and metalloids in bulk and particle size fractions of soils from coal-mine brownfield and implications on human health. Chemosphere 172, 505-515.doi: 10.1016/j.chemosphere.2017.01.021

Jorge Mendoza C., Tatiana Garrido R., Cristian Quilodrán R., Matías Segovia C., José and Parada A. (2017). Evaluation of the bioaccessible gastric and intestinal fractions of heavy metals in contaminated soils by means of a simple bioaccessibility extraction test. Chemosphere 176, 81-88. doi: 10.1016/j.chemosphere.2017.02.066
Müller, G. (1979). Heavy metals in the sediment of the Rhine - Changes seity. Umsch Wissenschaft Technik 79, 778-783.

Punshon, T., Carey, A. M., Ricachenevsky, F. K., and Meharg, A. A. (2018). Elemental distribution in developing rice grains and the effect of flag-leaf arsenate exposure. Environ. Exp. Bot. 149, 51-58. doi: 10.1016/j.envexpbot.2018.02.007

Qing, X., Yutong, Z., and Shenggao, L. (2015). Assessment of heavy metal pollution and human health risk in urban soils of steel industrial city (Anshan), Liaoning, Northeast China. Ecotoxicol. Environ. Saf. 120, 377-385. doi: 10.1016/j.ecoenv.2015.06.019

Ran, J., Wang, D., Wang, C., Zhang, G., and Zhang, H. (2016). Heavy metal contents, distribution, and prediction in a regional soil-wheat system. Sci. Tot. Environ. 544, 422-431.doi: 10.1016/j.scitotenv.2015.11.105

Ricachenevsky, F. K., de Araújo, A. T. Jr., Fett, J. P., and Sperotto, R. A. (2018). You shall not pass: root vacuoles as a symplastic checkpoint for metal translocation to shoots and possible application to grain nutritional quality. Front. Plant Sci. 9:412. doi: 10.3389/fpls.2018.00412

Ricachenevsky, F. K., Menguer, P. K., Sperotto, R. A., and Fett, J. P. (2015). Got to hide your $\mathrm{Zn}$ away: molecular control of $\mathrm{Zn}$ accumulation and biotechnological applications. Plant Sci. 236, 1-17. doi: 10.1016/j.plantsci.2015. 03.009

Saidur, M. R., Abdul Aziza, A. R., and Basirun, W. J. (2017). Recent advances in DNA-based electrochemical biosensors for heavy metal ion detection: a review. Biosens. Bioelectr. 90, 125-139. doi: 10.1016/j.bios.2016.11.039

Silva, M. L. S., Vitti, G. C., and Trevizam, A. R. (2007). Concentration of heavy metals in grain of plants cultivated in soil with different contamination levels. Pesq. Agropec. Bras. 42, 527-535. doi: 10.1590/S0100-204X2007000400011

Singh, A., Sharma, R. K., Agrawal, M., and Marshall, F. M. (2010). Health risk assessment of heavy metals via dietary intake of foodstuffs from the wastewater irrigated site of a dry tropical area of India. Food Chem. Toxi. 48, 611-619. doi: 10.1016/j.fct.2009.11.041

Suarez-Tapia, A., Kucheryavskiy, S. V., Christensen, B. T., Ingrid, K., Thomsen, I. K., and Rasmussen, J. (2017). Limitation of multi-elemental fingerprinting of wheat grains: effect of cultivar, sowing date, and nutrient management. J. Cereal Sci. 76, 76-84. doi: 10.1016/j.jcs.2017.05.015

Tchounwou, P. B., Yedjou, C. G., Patlolla, A. K., and Sutton, D. J. (2012). Heavy metals toxicity and the environment. Mol. Clin. Environ. Toxicol. 101, 133-164. doi: 10.1007/978-3-7643-8340-4_6

Zhang, H., Huang, B., Dong, L., Hu, W., Akhtar, M. S., and Qu, M. (2017). Accumulation, sources and health risks of trace metals in elevated geochemical background soils used for greenhouse vegetable production in southwestern China. Ecotoxicol. Environ. Saf. 137, 233-239. doi: 10.1016/j.ecoenv.2016. 12.010

Zheng, N., Liu, J., Wang, Q., and Liang, Z. (2010). Health risk assessment of heavy metal exposure to street dust in the zinc smelting district, Northeast of China. Sci. Total Environ. 408, 726-733. doi: 10.1016/j.scitotenv.2009.10.075

Conflict of Interest Statement: The authors declare that the research was conducted in the absence of any commercial or financial relationships that could be construed as a potential conflict of interest.

Copyright (c) 2018 da Rosa Couto, Comin, Souza, Ricachenevsky, Lana, Gatiboni, Ceretta and Brunetto. This is an open-access article distributed under the terms of the Creative Commons Attribution License (CC BY). The use, distribution or reproduction in other forums is permitted, provided the original author(s) and the copyright owner are credited and that the original publication in this journal is cited, in accordance with accepted academic practice. No use, distribution or reproduction is permitted which does not comply with these terms. 